Apuntes Universitarios, 2020: 10(1), Enero-Marzo

ISSN: 2304-0335 DOI: https://doi.org/10.17162/au.v10i1.414

\title{
Aportes a la teoría del diseño inteligente desde los contenidos curriculares de la genética molecular
}

\section{Contributions to the intelligent design theory from the curricular contents of molecular genetics}

\author{
Tamara Molero $^{1 \text { a }}$; Jairo Utate García ${ }^{2}$ \\ Universidad Adventista Dominicana. Santo Domingo, República Dominicana ${ }^{1}$ \\ Universidad Adventista Dominicana. Santo Domingo, República Dominicana ${ }^{2}$ \\ Orcid ID: https://orcid.org/0000-0003-4757-2455 ${ }^{1}$ \\ Orcid ID: https://orcid.org/0000-0002-4701-8588 ${ }^{2}$
}

Recibido: 09 de marzo de 2019

Aceptado: 1 de octubre 2019

\section{Resumen}

El estudio de los complejos procesos ultracelulares de los ácidos nucleicos es un tema debatido como argumento científico a favor del Diseño Inteligente (DI). El objetivo de este trabajo fue analizar algunos procesos moleculares de los ácidos nucleicos que sugieren la confirmación de la teoría del DI, a través de la técnica de análisis documental de contenido. En primer lugar, la estructura química del ADN y la combinación de las bases nitrogenadas refleja que la información genética de cada ser creado es una mezcla original de las bases nitrogenadas que hace a cada individuo único en la historia del mundo. En segundo lugar, al estudiar los procesos de replicación y reparación del $\mathrm{ADN}$ se observa que cada enzima cumple su función de una forma coordinada y organizada, evitando la ocurrencia de errores; y en caso de que así ocurra, la célula ha dispuesto de mecanismos de reparación finísimos que corrigen de la mejor forma posible estas alteraciones. En tercer lugar, el proceso de fabricación de proteínas y su control altamente regulado, involucra la participación de enzimas y proteínas que trabajan organizadamente para lograr proteínas, algunas de ellas irrepetibles, que definen la identidad del ser vivo. Como última parte, se discute el mecanismo de empaquetamiento de los ácidos nucleicos. Esta combinación de procesos, organización y confección de maquinarias especiales y precisas definitivamente provienen de un 
diseño meditado de un ser superior. Finalmente, se redactó una sección donde se expone ideas sobre la defensa de la Teoría del Diseño Inteligente.

Palabras clave: diseño inteligente, bases moleculares, ácidos nucleicos.

\begin{abstract}
The study of the complex ultracellular processes of nucleic acids is a subject debated as a scientific argument in favor of Intelligent Design (ID). The objective of this work was to analyze some molecular processes of the nucleic acids that suggest the confirmation of the ID theory, through the technique of documentary content analysis. First, the chemical structure of DNA and the combination of nitrogenous bases reflects that the genetic information of each created being is an original mixture of nitrogenous bases that makes each individual unique in the history of the world. Secondly, by studying the processes of DNA replication and repair, it is observed that each enzyme fulfills its function in a coordinated and organized manner avoiding the occurrence of errors and, should this occur, the cell has had very fine repair mechanisms. that correct these alterations in the best possible way. Third, the process of manufacturing proteins and their highly regulated control involves the participation of enzymes and proteins that work in an organized manner to obtain proteins, some of them unrepeatable, that define the identity of the living being. The final part discusses the impressive and perfect packaging mechanism of nucleic acids. This combination of processes, organization and preparation of special and precise machineries definitely come from a meditated design of a superior being. Finally, a section was written where ideas about the defense of Intelligent Design Theory are exposed.
\end{abstract}

Key words: Intelligent design, molecular bases, nucleic acids.

\title{
Introducción
}

Una de las grandes interrogantes del ser humano es la relativa a su origen. Como lo dijeran Hawkin y Mlodinow (2010): “cada uno de nosotros existe durante un tiempo muy breve y en dicho intervalo tan solo explora una parte diminuta del conjunto del universo... Nos hemos hecho siempre una multitud de preguntas... ¿De dónde viene todo lo que nos rodea? ¿Necesitó el universo un Creador?” (p. 1). En busca de esas respuestas, se enfrenta un dilema: la teoría evolucionista intenta hacer interpretación de hechos científicos para dar una explicación al origen del universo, así como al origen mismo del ser humano. Por otro lado, existen creencias donde se presenta un Ser superior como Creador, y al ser humano como su criatura. En este sentido, la escuela es un espacio fértil para desarrollar en el alumnado ideas propias sobre su origen, ideas que desafíen el intelecto, que estén fundamentadas en procesos naturales, científicos; y que orienten sus vidas desde un paradigma inteligente. Ante esta situación, emerge un modelo alternativo que 
apoya la teoría creacionista bíblica, conocido como teoría del Diseño Inteligente (DI), la cual cuenta cada vez con más amplia consideración (Roth, 2010).

La teoría del DI [Diseño inteligente], llamada así en 1991 por Phillip E. Johnson, sostiene que ciertos rasgos del universo y de los seres vivos se explican mejor por una causa inteligente, en contraste a un proceso no dirigido como el de la selección natural (Johnson, 2011). El DI propone la existencia de un diseñador inteligente, basándose en tres argumentos científicos que la respaldan (Collado, 2007): a.- el universo bien afinado (Denton, 1996; Denton, 1998); b.- la complejidad irreductible, propuesta por Behe (1996); y c.- la complejidad específica (Dembski, 1999).

Denton expone que la complejidad en el mundo natural no puede ser formulada sobre la agregación de cambios producidos y organizados al azar; por el contrario, fue diseñada para que pudiera albergar la vida. Por lo tanto, desde su inicio, el universo estuvo "bien afinado".

Por su lado, Behe sustenta que, ante la organización del universo a nivel astronómico, biológico u orgánico, se hace evidente una complejidad irreductible; es decir, que es imposible imaginar que el desarrollo y la organización de sistemas complejos como los seres vivos o algunas causalidades en las leyes cósmicas y planetarias sean producto del azar, lo que implica la existencia de un diseño y, por ende, de un Diseñador. Esto implica que todo el universo tiene una finalidad, por lo cual no hay espacio para especulaciones al respecto.

Mientras que Dembski, en su argumento de la complejidad específica, sostiene que los procesos de los seres vivos, especialmente los patrones de secuencias moleculares en las macromoléculas biológicas (como las proteínas y el ADN), poseen una probabilidad de que acontezcan por mero azar, que es numéricamente menor a cierto valor teórico. En este contexto, cuando algo tiene complejidad específica, se asume que fue producido de una causa inteligente, y no el producto de un proceso natural (Hortolá y Carbonell, 2007).

La finalidad de este artículo no es discutir las implicaciones filosóficas de la teoría del DI, ni de las tres ideas centrales sobre las que se apoya; solo se pretende asumir que dichas ideas sugieren la idea de la perfección del sistema. Esta perfección puede evidenciarse en las bases moleculares de la ultraestructura celular de todos los organismos existentes. Esto puede sugerir la elaboración de un contenido curricular que pueda resultar útil al integrar valores y creencias en los aprendizajes del alumnado mientras se trabaja en la escuela. Por lo tanto, el objetivo de este trabajo es analizar algunos contenidos curriculares en genética, relativos a los procesos moleculares de los ácidos nucleicos, que sugieren la confirmación de la teoría del DI. 


\section{Materiales y método}

La presente investigación es de tipo documental, y se ubica en los análisis documentales de contenido, definida como una operación intelectual que da lugar a un subproducto o documento secundario el cual actúa como intermediario o instrumento de búsqueda obligado entre el documento original y el usuario que solicita información. La creación de este subproducto implica la integración, organización y evaluación de la información teórica y empírica existente sobre un problema, focalizando el progreso de la investigación actual.

Castillo (2005) lo define como un proceso analítico-sintético, en el cual la información referida a un tema es estudiada, interpretada y sintetizada minuciosamente para dar lugar a un nuevo documento que lo representa de modo abreviado pero preciso, caracterizado por contener una información concentrada de los documentos originales que pueden ser consultados con facilidad ofreciendo las primeras noticias de la existencia de aquellos sin alguna interpretación o crítica.

A fin de realizar esta investigación, se emplearon bases de datos documentales impresas y electrónicas, desde las cuales se recolectó, clasificó, analizó y resumió el contenido de artículos científicos, tesis de grado, memorias de eventos y libros referidos a las bases moleculares que apoyan la teoría del DI.

Toda la información fue clasificada y categorizada en cuatro secciones: a.- la estructura química del ADN y la combinación de las bases nitrogenadas; b.- los procesos de replicación y reparación del ADN; c.- el sistema de síntesis de las proteínas y el control de la transcripción; y la parte d.- el mecanismo de empaquetamiento del ADN. Para finalizar, en el análisis se redactó una última sección donde se exponen ciertas ideas en la defensa de la teoría del DI.

\section{Resultados y discusión}

En lo siguiente, se exponen algunos contenidos curriculares que se estudian regularmente en la asignatura de genética, enfocados desde la perspectiva del DI.

\section{La estructura química del ADN y combinación de las bases nitrogenadas}

La información genética particular de cada ser creado se refleja en una mezcla original de las bases nitrogenadas que hace a cada individuo único en la historia del mundo. El descubrimiento del código genético ha mostrado de qué manera la combinación de cuatro diferentes tipos de bases nucleótidas (adenina [A], timina $[\mathrm{T}]$, citosina $[\mathrm{C}]$ y guanina $[\mathrm{G}]$ en unidades codificadas de tres 
bases en la cadena de $\mathrm{ADN}$ ), puede dictar el orden de cualquiera de los veinte aminoácidos que pueden estructurar una proteína.

Las combinaciones complicadas de esas cuatro bases nitrogenadas a lo largo de cadena de $\mathrm{ADN}$-que se manifiestan en millones de posibles combinaciones-finalizan en la síntesis inteligente de proteínas que determinan, no solamente el fenotipo particular de cada individuo, sino las características comunes de un grupo de individuos que se identifican en una especie biológica. Estas combinaciones no aparecen de manera azarosa en el ADN, sino que siguen un orden predeterminado, a fin de lograr la síntesis de proteínas específicas que participarán en diferentes procesos metabólicos y fisiológicos dentro del organismo. Todo este sistema es complejo y codificado, y un simple cambio en este orden establecido, se traduciría en un descalabro genético que daría origen a mutaciones, la mayoría de ellas perjudiciales.

Por otro lado, la perfección en la ubicación de cada base nitrogenada en la cadena de $\mathrm{ADN}$ - para que se codifique una secuencia particular de aminoácidos y se formen proteínas funcionales y específicas, y no otras - trae a la mente racional la idea que, detrás de esta organización detallada, debe haber un ser inteligente y superior que diseñó todo el sistema.

Es necesario apuntar que esta secuencia de bases nitrogenadas es similar entre los individuos que forman una misma especie biológica y que, por supuesto, tendrán la misma estructura anatómica y fisiológica. Sin embargo, cada individuo posee bases nitrogenadas en su $\mathrm{ADN}$ que le permiten producir proteínas casi exclusivas que determinan su fenotipo particular, gracias a la herencia recibida de sus progenitores.

De esta idea presentada se puede enriquecer la discusión desde dos aspectos: el primero, referido a la noción que cada ser fue creado por Dios para que fuera único y perfecto. No existió, ni existirá en el mundo, un organismo con la misma información genética de otro, con casos excepcionales de gemelos univitelinos. Aun en estos casos, el ambiente y la sociedad ejercen una influencia importante en la diferenciación fenotípica de cada individuo. Considerando este contexto, se entiende que este Diseñador inteligente se dedicó a configurar con detalle y agudeza la combinación genética de las bases nitrogenadas de cada organismo, que los hacen ser únicos en la naturaleza.

El segundo aspecto se refiere a la noción de especiación. Se había comentado que la combinación de bases nitrogenadas similares daba como resultados la formación de organismos con igual estructura anatómica y morfológica y que constituyen una especie biológica. En este 
caso, la Biblia, en Génesis 1 y 6, señala la creación de "grupos" de seres vivos (del hebreo min, traducido como “especie" en Gén. 6:20; o "género" en Gén. 1:21); no obstante, los hechos muestran que un gran número de nuevas especies (según la taxonomía moderna) se diferenciaron al día de hoy debido a cruzamiento, hibridación y, en general, por diferentes mecanismos de especiación. De esa forma pudieron surgir nuevos grupos de organismos como resultado natural de una necesidad de adaptación a las nuevas condiciones medioambientales impuestas, y detrás de ellos, nuevas combinaciones genéticas que les permitieron a estos organismos desarrollar características posibles para la adaptación.

Evidentemente, la aparición de estas novedades no pudo ser producto de un hecho al azar que implique cifras astronómicas de tiempo y precisión a la vez, sino de un proceso planificado dentro de la biología de los organismos postdiluvianos que permitieron su adaptación, reproducción y diseminación sobre la tierra, como lo infiere el argumento de complejidad específica anteriormente mencionado.

\section{Los procesos de replicación y reparación del ADN}

Es asombroso estudiar los complejos procesos de la replicación del ADN. Para explicar este mecanismo, didácticamente se recurre a dividirlo en tres etapas: inicio, elongación y terminación de la replicación. En estas se observa un desfile de enzimas y proteínas que cumplen una función específica durante dicho proceso. La participación de cada una ocurre de manera coordinada y organizada. No puede, por ejemplo, actuar la helicasa sin que la topoisomerasa haya desenrollado la cadena de $\mathrm{ADN}$. De igual manera, la enzima ADN polimerasa no puede colocar el primer desoxinucleotrifosfato en la creación de la nueva cadena de $\mathrm{ADN}$, sin que antes la enzima primasa sintetice el fragmento de ARN cebador que aporte el extremo 3' $\mathrm{OH}$ libre, imprescindible para que la polimerasa pueda actuar.

Es necesario considerar la manera creativa e inteligente como se soluciona el problema de las direcciones opuestas en la molécula de $\mathrm{ADN}$ durante la replicación. Siendo que una cadena gira en dirección $3^{\prime} \rightarrow 5^{\prime}$ y la otra en dirección $5^{\prime} \rightarrow 3^{\prime}$, y que la enzima ADN polimerasa sólo incorpora nucleótido en dirección 5 ' $\rightarrow$ 3' (que traía como consecuencia que la otra cadena no se pudiera sintetizar), lo solucionó creando la nueva cadena a través de la unión de fragmentos-los fragmentos de Okasaki - que se forman paulatinamente a través de un complejo mecanismo que involucra el pliegue de la cadena con dirección $5^{\prime} \rightarrow 3^{\prime}$ y la participación de enzimas específicas, 
encargadas de formar y unir los fragmentos, con el fin que las dos nuevas cadenas hijas queden en igual condiciones para ser repartidas a las nuevas células hijas en la conclusión del proceso.

Cabe señalar la gran producción celular de los organismos multicelulares, como parte de sus procesos normales de mantenimiento y reparación tisular. Cada vez que una célula se reproduce, duplica millones y miles de millones de bases nucleótidas. En el caso del hombre, 3,000 millones de pares de bases nucleótidas se forman cada vez que el cuerpo realiza ADN para una célula. En el proceso de duplicar esta información, pueden ocurrir algunos errores de copiado. Mientras algunos de estos errores parecen hacer poca diferencia, otros pueden ser letales para un organismo. Sin embargo, la célula posee mecanismos muy eficientes para afinar el proceso de copiado. Estos mecanismos revisan el ADN y corrigen los errores, lo que asegura una alta fidelidad en el copiado y, por ende, la estabilidad del material genético.

Diversos son los mecanismos de reparación durante la duplicación del ADN, pero todos ellos tienen la finalidad de garantizar la transmisión fiel de la información genética a las nuevas células y, en última instancia, a las nuevas generaciones. Dichos errores pueden ocurrir, provocados por agentes físicos y químicos, que tienen la capacidad de alterar la incorporación de una o varias bases nitrogenadas o la estructura del $\mathrm{ADN}$, con los consecuentes errores en la replicación. No obstante, el Diseñador inteligente dispuso de mecanismos altamente complicados, pero organizados y perfectos, para corregir la aparición de estos equívocos. Estos mecanismos se realizan a través de enzimas con capacidades "inteligentes" de eliminar las bases modificadas e incorporar las combinaciones correctas.

Estos mecanismos han sido descubiertos y estudiados con amplitud en organismos procarióticos, pero aún resta una gran cantidad por descifrar desde el punto de vista bioquímico y molecular, tanto en bacterias como en células eucarióticas. Esto puede aportar una mejor comprensión de las bases fundamentales de la replicación y mecanismos de reparación del ADN.

En este punto se puede lanzar diversas interrogantes: ¿estaría dentro de una lógica natural afirmar que los mecanismos de reparación del ADN para eliminar — o por lo menos minimizarlos errores durante la replicación de ácidos nucleicos surgieron fortuitamente? ¿Pudieron surgir estos mecanismos ultracelulares, perfectos y altamente complejos sin la necesidad de una mano diseñadora que organizara todo con tanta fidelidad, como para evitar cualquier error que podría poner en riesgo la integridad y el bienestar de las especies creadas? 


\section{El sistema de síntesis de proteínas y control de la transcripción}

El proceso de fabricación de proteínas a partir de la información presente en los genes, es complejo y altamente regulado. Los genes deben ser "apagados" o "activados" según se necesite una específica proteína en el organismo. Los investigadores han descubierto un buen número de mecanismos de control de genes: unos reprimen la actividad de los genes, otros los activan. Además, algunos genes tienen más de un mecanismo de control.

Asimismo, se ha descubierto que las células contienen un sistema técnico complejo de procesamiento y almacenamiento de información, permitiendo que estas funcionen como un sistema informático sofisticado, aunque con una eficiencia, precisión y flexibilidad mucho mayores que la de cualquier computadora.

En principio, la síntesis de una enzima inicia con una señal del organismo que indica la necesidad de ella, lo que desencadena una serie de procesos para "encender" la fábrica. Esto involucra la participación de proteínas reguladoras adicionales que estimulan las regiones promotoras del $\mathrm{ADN}$ e indican a las regiones operadoras que la primera etapa de la síntesis, la transcripción, debe ser realizada. Una vez aprobada la apertura del mecanismo, se procede a copiar la información genética del $\mathrm{ADN}$ de manera fiel según complementariedad de las bases nitrogenadas formándose un ARN mensajero (ARNm). La enzima ARN polimerasa o transcriptasa, incorpora los ribonucleótidos, uno a uno, leyendo previamente el mensaje en la cadena codogénica del ADN hasta formarse la cadena de ARNm. Una vez completado este proceso se da paso a la segunda etapa de la síntesis proteica, la traducción.

La traducción ocurre en los ribosomas de las células. En esta etapa el ARNm se ajusta entre la subunidad menor y mayor de ribosoma para que el ARN de transferencia (ARNt) traduzca la información o lenguaje del $\mathrm{ADN}$ a la información o lenguaje de las proteínas. Para ello, en el ribosoma se dispone de zonas o sedes donde se ubican los codones o tripletes del ARNm, los cuales van a ser leídos y descifrados por el ARNt a través del código genético y traducidos en aminoácidos para la formación de las cadenas peptídicas, asemejándose al funcionamiento de una fábrica, la fábrica molecular. Esta fábrica sólo se detiene cuando encuentra otra señal que indica la finalización del proceso.

Estas pequeñas pinceladas del proceso de síntesis proteicas apenas son un breve vestigio de los verdaderos e intrincados mecanismos moleculares que operan. Durante toda esta fabricación, participan un considerable número de enzimas, proteínas, factores de iniciación, elongación y 
terminación, compuestos químicos $\mathrm{y}$ otras estructuras que trabajan cronometrada $\mathrm{y}$ organizadamente para lograr el producto deseado.

En el caso de las células eucariotas, la síntesis de proteínas es mucho más compleja. Debido a que este $\mathrm{ADN}$ contiene regiones codificadoras y no codificadoras de proteínas, la célula debe descartar eficientemente aquellas regiones que no se traducirán a proteínas (intrones), quedándose solamente con las que sí tienen carácter funcional (exones). Por lo tanto, este ARNm debe sufrir un proceso de maduración a través del mecanismo llamado "empalme" o splicing, donde se observa una serie de detalles perfectos para identificar cuales regiones del ARNm deben ser eliminadas por las enzimas y cuáles no. Adicionalmente, este ARNm maduro debe realizar un viaje, desde el núcleo al citoplasma, donde queda expuesto a enzimas degradadoras que podrían destruir o cortar el mensaje. Para evitar este problema, el Diseñador Superior dispuso de la formación de estructuras protectoras en ambos extremos del ARNm que lo protegiera contra cualquier amenaza celular que pudiera alterar el mensaje con el objeto de que la información copiada del ADN llegara sin ninguna alteración al ribosoma.

La sincronización de estos mecanismos moleculares, ¿no son evidencias de una planificación, más allá de lo que la mente humana puede entender? No cabe la menor duda que esta combinación de procesos, organización y confección de maquinarias especiales y precisas para la célula tuvo que provenir de un diseño meditado y bien pensado, y que por ningún caso pudieron suceder por vana casualidad. El grado de ordenamiento y especialización que se encuentra en la naturaleza, ¿No parece estar más allá del azar que podríamos esperar si no hubiese algún tipo de diseño inherente detrás de todo?

Como lo afirman Bowie y Sauer (1989), “dado que las propiedades químicas del ADN permiten un vasto conjunto de ordenamientos combinatorios posibles de bases nucleotídicas, cualquier secuencia particular será por fuerza altamente improbable en la capacidad de transmitir información. Sin embargo, dentro del conjunto de posibles secuencias, muy pocas producirán proteínas funcionales, dado el sistema multimolecular de expresión génica situado en el interior de la célula" (p. 2153).

\section{El mecanismo de empaquetamiento del ADN}

En la naturaleza se encuentra una gama de organismos que va desde seres ultramicroscópicos como los virus, hasta células eucarióticas con una alta complejidad estructural, 
pasando por las células procariotas y micoplasmas, entre otros. Desde el punto de vista de la organización genética, estos organismos oscilan desde los más sencillos hasta los más complejos.

Los virus son los organismos más diversos en cuanto a ácidos nucleicos se refiere, pues su material genético puede ser guardado en un ARN o en un ADN asumiendo diversidad de formas y conformaciones, lo que hace que sean un grupo bastante heterogéneo. Pese a ello, los virus se caracterizan por su simplicidad estructural, conformada básicamente por un ácido nucleico que está envuelto por una cápside o cabeza de proteínas.

Caso contrario ocurre en las células procariotas y eucariotas. Al observar la organización genética del $\mathrm{ADN}$ procariótico, pese a que no está separado del citoplasma a través de una membrana nuclear, se nota un grado de organización tal que hoy se conoce como el cromosoma bacteriano. Este ADN se encuentra empaquetado en forma de lazos llamados "dominios", alrededor de un armazón proteico, y en cada dominio se encuentran ubicados y relacionados todos los genes que participan en una misma ruta metabólica. Eso se traduce en una eficiencia celular. Además, dentro de las bacterias pueden existir los "plásmidos", que son secuencias de ADN extracromosómico que les confieren nuevas capacidades, como ser resistentes a antibióticos o colonizar habitas extremos, gracias a la presencia de genes específicos que muchas veces son únicos en las especies.

Llama la atención algunos de los mecanismos de defensa bacterianos que utilizan su propia maquinaria genética. Por ejemplo, cuando un virus trata de infectar una batería, ésta activa unas enzimas que funcionan como tijeras moleculares cortando el ácido nucleico invasor, evitando que su maquinaria molecular sea secuestrada. El descubrimiento de estas enzimas dio paso a lo que hoy se conoce como las "enzimas de restricción" usadas en las técnicas de ingeniería genética para cortar el ADN. Estas enzimas cortan en sitios muy específicos del ADN, al igual como lo hacen las bacterias al momento de atacar a su virus oponente. Entender cómo una bacteria detecta la secuencia de bases nitrogenadas de un virus y usa la enzima específica para cortar el ácido nucleico, exhibe la necesidad de un proceso de diseño que sería imposible que llegara a afinarse por eventos casuales.

Por otro lado, es sorprendente observar los detalles en la perfección del proceso de empaquetamiento del ADN eucariota que va en sincronización con el ciclo de vida celular. Luego de la formación de una nueva célula, los subsiguientes pasos son: la entrada de ella en interfase, donde el ADN debe descondensarse o desenrollarse para poder replicar el material genético; y 
luego entrar en mitosis para lo cual tiene que condensar o empaquetar nuevamente su material genético.

Ya se ha comentado en los apartados anteriores, como se efectúa el proceso de desenrollar el ADN para replicarlo; ahora se aborda la realización del empaquetado. Para ello, es importante entender que el ADN está desnudo, es decir, que no está asociado a nucleoproteínas (histonas) y tiene que empacarse para poder ser repartido en las células hijas.

Esto se debe a un perfecto mecanismo de empaquetamiento en la cual el ADN se enrolla alrededor de un octámero de histonas para formar una fibra de cromatina de 10 nanómetros (nm) conformado por los nucleosomas. Esta fibra seguirá enrollándose sobre sí misma, formando la fibra de cromatina de $30 \mathrm{~nm}$ y así ésta se seguirá encogiendo formando fibras de grosores mayores hasta que consiga un esqueleto de proteínas no histónicas, también llamado "andamio" o scaffol, alrededor de la cual se va a disponer a manera de lazos para darle la forma al cromosoma metafásico. Nuevamente, toda esta síntesis requiere ser enriquecida por la participación de otras enzimas y proteínas que coordinan y controlan todo el proceso, a fin de tener una idea más clara de la impresionante complejidad química y estructural. Ahora, aparece la pregunta: ¿cómo es posible entender que este conjunto organizado de procesos interconectados y perfectamente planificados, hallan surgidos por un simple golpe de suerte? Esto exige afirmar la concepción de un diseño inteligente.

\section{EI eje central de los procesos moleculares está bajo la óptica del DI}

Los procesos moleculares reseñados anteriormente, se ajustan perfectamente al principio de complejidad irreductible de la teoría del DI. Su proponente, Behe (1996), declara lo siguiente: “con la expresión sistema irreductiblemente complejo [sic] me refiero a un solo sistema compuesto por varias piezas armónicas e interactuantes que contribuyen a la función básica, en el cual la eliminación de cualquiera de estas piezas impide al sistema funcionar" (p. 55). Y, efectivamente, esto es lo que se espera que ocurra si algunos de los pequeños componentes de estos complejos procesos moleculares dejan de funcionar o desaparecen. En este caso, se considera seriamente que existe un Ser Superior que ha creado todo el universo con un diseño inteligente implícito, con unas leyes y mecanismos tan particulares, precisos, puntuales, minuciosos y exactos, que sin ellos sería imposible la estabilidad del universo y la vida sobre el planeta.

Se reconoce que existen aún misterios que el hombre puede descubrir en la biología molecular, que a su vez explican gran número de hechos asombrosos de la creación de Dios. 
Muchas de estas "cajas negras" aún no se han abierto a los ojos, quizás de manera intencionada, pues Dios controla los tiempos y conoce las limitaciones de la mente humana.

En este sentido, Flori y Rasolofomasoandro (2000) afirman que la aceptación de Dios como diseñador inteligente, resuelve el problema de la aparición de la vida, ya que no sería fruto de la casualidad, sino de una voluntad divina. No es una ascensión lenta, ciega y vacilante hacia formas cada vez más complejas sino una creación de Dios. Desde el conocimiento ordinario de la naturaleza, estas evidencias hacen difícil aceptar que los complicados sistemas biológicos puedan haber llegado a su estado actual como fruto de los mecanismos darwinianos hechos realidad por el caos durante el transcurso de grandes cantidades de tiempo.

\section{Conclusiones}

Los sistemas moleculares exponen demasiada complejidad como para invocar un origen por azar. Ejemplos dignos de notar son: las combinaciones únicas de las bases nitrogenadas que hace a cada individuo único genéticamente en la historia del mundo; mecanismos precisos para la replicación del ADN y de su edición para corregir errores de copiado en la síntesis de DNA; un sistema para la síntesis de las proteínas a partir de información codificada en el ADN, incluyendo mecanismos de decodificación y lectura, sistemas complejos de control de genes y la organización perfecta de los ácidos nucleicos desde organismo poco complejos a los más complejos.

Todos estos sistemas son intrincados, altamente programados y con precisión absoluta. Abordados en la escuela desde una perspectiva integral, lleva a concluir que no parece posible que puedan haber surgido por casualidad. Estos sistemas son mucho más complejos que cualquier computadora y ¿es lógico pensar en un origen espontaneo y azaroso para una máquina de éstas?

Por otro lado, las Escrituras conducen a un origen sobrenatural, mostrando al autor del universo y de la vida aquí en la tierra. Hebreos 1: 10-12, enfatiza: “Tú, oh Señor, en el principio fundaste la tierra, y los cielos son obra de tus manos. Ellos perecerán, mas tú permaneces... Todos ellos se envejecerán... y serán mudados... pero tú eres el mismo, y tus años no acabarán”.

La ciencia, en su correcta dimensión, vista a través de la teoría del DI, nos aproxima a una explicación racional de los hechos científicos, a favor del creacionismo y a favor de su Autor. 


\section{Referencias}

Behe, M. J. (1996). La caja negra de Darwin. El reto de la bioquímica a la evolución. Chile: Editorial Andrés Bello.

Bowie J. y Sauer, R. (1989). Identifying determinants of folding and activity for a protein of unknown sequences: tolerance to aminoacid substitution. Proceedings of the National Academy of Sciences, USA 86: 2152-56.

Castillo, L. (2005). Análisis documental. Biblioteconomía. 18pp. Disponible en_http://www. uv.es/macas/T5.pdf. Consultado el 20/05/2016.

Collado, S. (2007). Análisis del diseño inteligente. Scripta Theologica, 39: 573-605.

Dembski, W. A. (1999). Intelligent Design: The Bridge between Science and Theology. EUA: InterVarsity Press. Pág, 105-200.

Denton, M. (1996). Evolution, A Theory in Crisis. EUA: Editorial Adler y Adler Publishers. 368 pp.

Denton, M. (1998). Nature's Destiny: How the Laws of Biology Reveal Purpose in the Universe. Londres: The Free Press.

Flori, J. y Rasolofomasoandro, H. (2000). En busca de los orígenes ¿Evolución o creación? España: Editorial Safeliz.

Hawkin, S. y Mlodinow, L. (2010). El gran diseño. España: Editorial Crítica.

Hortolá, P. y Carbonell, E. (2007). Creación versus evolución: del origen de las especies al diseño inteligente. Revista de Historia de la Medicina y de la Ciencia LIX(1): 261-274.

Johnson, P. E. (2011). Proceso a Darwin. España: Editorial SEDIN.

Roth, A. (2009). La ciencia descubre a Dios. España: Editorial SAFELIZ. 